\title{
A 7-13 GHz low-noise tuned optical front-end amplifier for heterodyne transmission system application
}

\author{
Ebskamp, Frank; Schiellerup, Gert; Høgdal, Morten
}

Published in:

I E E E - M T T S International Microwave Symposium. Digest

Link to article, DOI:

10.1109/MWSYM.1991.147070

Publication date:

1991

Document Version

Publisher's PDF, also known as Version of record

Link back to DTU Orbit

Citation (APA):

Ebskamp, F., Schiellerup, G., \& Høgdal, M. (1991). A 7-13 GHz low-noise tuned optical front-end amplifier for heterodyne transmission system application. I E E E - M T T S International Microwave Symposium. Digest, 2, 585-588. https://doi.org/10.1109/MWSYM.1991.147070

\section{General rights}

Copyright and moral rights for the publications made accessible in the public portal are retained by the authors and/or other copyright owners and it is a condition of accessing publications that users recognise and abide by the legal requirements associated with these rights.

- Users may download and print one copy of any publication from the public portal for the purpose of private study or research.

- You may not further distribute the material or use it for any profit-making activity or commercial gain

- You may freely distribute the URL identifying the publication in the public portal 


\title{
A 7-13 GHz LOW-NOISE TUNED OPTICAL FRONT-END AMPLIFIER FOR HETERODYNE TRANSMISSION SYSTEM APPLICATION
}

\author{
Frank Ebskamp, Gert Schiellerup and Morten Høgdal \\ Center for Broadband Telecommunications, Electromagnetics Institute \\ Technical University of Denmark, Bld. 348, DK-2800 Lyngby, Denmark

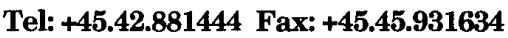

\begin{abstract}
We present a 7 - $13 \mathrm{GHz}$ low-noise bandpass tuned optical front-end amplifier, showing $46 \pm 1 \mathrm{~dB} \Omega$ transimpedance, and a noise spectral density around $12 \mathrm{pA} / \sqrt{\mathrm{Hz}}$. This is the first time such a flat response and low noise were obtained simultaneously at these frequencies, without any further equalization. The front-end was used in an optical 2.5 Gbit/s coherent CPFSK system experiment, resulting in a sensitivity of $-41.7 \mathrm{dBm}$ at $\mathrm{BER}=10^{-9}$.
\end{abstract}

\section{INTRODUCTION}

Since optical fiber transmission systems have found widespread commercial application in communication networks, interest has increased for more advanced type of optical systems, using coherent modulation and heterodyne detection methods. In such optical coherent systems, the optical front-end amplifier is a crucial component, since it has to operate at a high intermediate frequency, at least twice the bit rate, over a large bandwidth and at the same time has to exhibit low noise. These stringent requirements are increasingly difficult to meet at high bit rates. An elegant way of designing such a front-end is by the use of a tuning network between the photodetector and the first transistor, which can yield a bandpass frequency characteristic and low noise within this band [1-3].

\section{SYSTEM REQUIREMENTS}

The tuned optical front-end amplifier was designed and constructed for use in a $2.5 \mathrm{Gbit} / \mathrm{s}$ CPFSK coherent transmission system $[4,5]$. One of the main features of this system is the use of a relatively high intermediate frequency, around $10.5 \mathrm{GHz}$. The choise of this intermediate frequency has the following advantages. The large separation between baseband and IF band makes it easier to perform signal processing both in the electrical and in the optical domain, as illustrated in [6]. Also, a number of microwave X-band components are commercially available. Due to the moderate relative bandwidth, other microwave components can be constructed using standard microstrip techniques. Finally, upgrading to higher bit rates is possible at the same intermediate frequency. The total laser linewidth in this system is $35 \mathrm{MHz}$. In order to accomodate this relatively large value, it is necessary to use a rather lagre modulation index of 1.25 and an IF bandwidth of approximately $5 \mathrm{GHz}$. Therefore, a front-end bandwidth of $8-13 \mathrm{GHz}$ is necessary, and an equivalent input noise current spectral density of around $12 \mathrm{pA} / \mathrm{VHz}$, in order to achieve local oscillator short noise dominated performance. In the following it is shown how these requirements were met. 


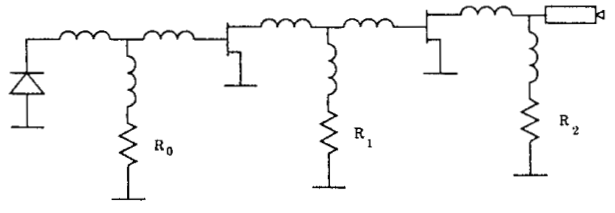

Figure 1. Schematic circuit diagram of the frontend amplifier.

\section{CIRCUIT DESIGN}

The schematic circuit diagram of the front-end amplifier is shown in figure 1. A PIN photodiode and two HEMT transistors were employed. A Tequivalent of a transformer network was used between the photodiode and the first transistor. This network reduces the influence of the input capacitance, consisting of the photodiode junction capacitance and the input capacitance of the first transistor, thus avoiding the $\mathrm{f}^{2}$ noise contribution which is found in conventional receivers [1]. An interstage microwave matching network and an output matching network were applied. No further equalization was used in this design. The low frequency characteristic is determined by the RL branches of the tuning and matching T-networks, whereas the high frequency response depends on the "arms" of the T-networks. The noise depends on the resistor $R_{0}$ in the tuning "leg" and the series resistance of the photodiode. Stability analysis of the circuit has been performed, and it was found that $R_{0}$ has a lower limit in order to avoid instabilities. An accurate model of the photodiode was obtained by measuring the frequency response of the device with an optical signal swept over $0-20 \mathrm{GHz}$, and the magnitude and phase of the reflection coefficient. In the circuit simulations, the S-parameters of the HEMT components were used, with modification for the transconductance of the individual devices.

\section{LAY-OUT AND MANUFACTURING}

The front-end amplifier was manufactured as a hybrid integrated circuit using a thin film technique on a $\mathrm{Al}_{2} \mathrm{O}_{3}$ substrate. The photodiode is a commercially available $26 \mathrm{GHz}$ InGaAs PIN chip device [7] and the transistors are NEC $20200 \mathrm{GaAs}$ HEMT chip devices. Bonding wires were used for interconnection, and they also provided the induction for the tuning and matching networks $[1,2]$. This is a very flexible approach, since individual adjustments of the bonding wire lengths are possible. Ground connections were made by via holes. The resistors were made as $\mathrm{NiCr}$ thin film resistors on the substrate. Microwave capacitors $(0.3 \mathrm{~mm} \times 0.3 \mathrm{~mm})$ were used as DC block and RF by-pass capacitors. A new flexible lay-out technique enabled monitoring and characterization of each manufacturing step, and thus verification of simulations. The lay-out is shown in figure 2.

FE 90 CBT

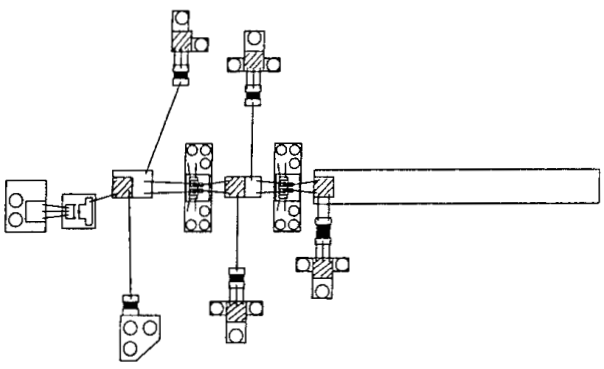

Figure 2. Lay-out of the front-end amplifier.

\section{CHARACTERIZATION}

The two-stage front-end amplifier, without the photodiode and without the input tuning network, was electrically characterized by measuring the S- 


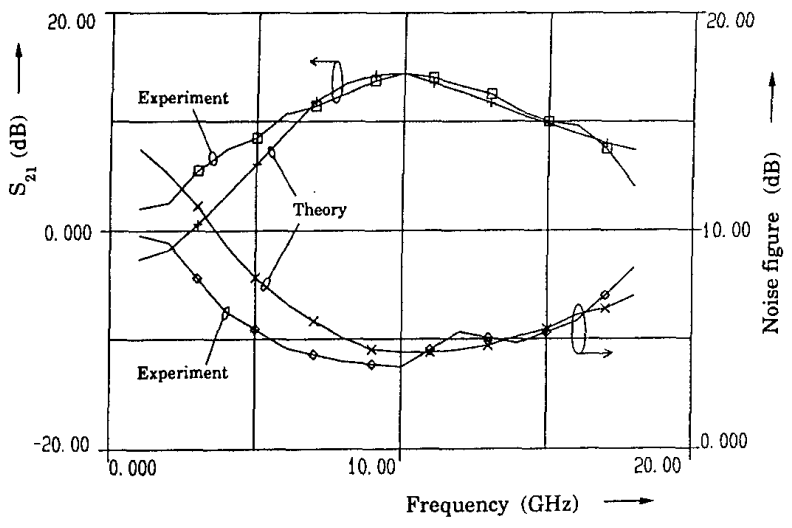

Figure 3. Measurement and simulation of $S_{21}$ and noise figure of the front-end amplifier, without photodiode and without tuning network.

parameters and the noise figure. As seen in figure 3 , the measured and simulated results of $S_{21}$ and the noise figure agree very well. After mounting of the photodiode, the transimpedance and noise of the front-end amplifier were measured as follows. The front-end was illuminated with an optical beat signal from a three-electrode DFB laser [8] and an external cavity laser, which was swept over $0-20$ $\mathrm{GHz}$. The absolute transimpedance was found by calibrating with a high speed photodiode. The circuit noise power was recorded with a spectrum

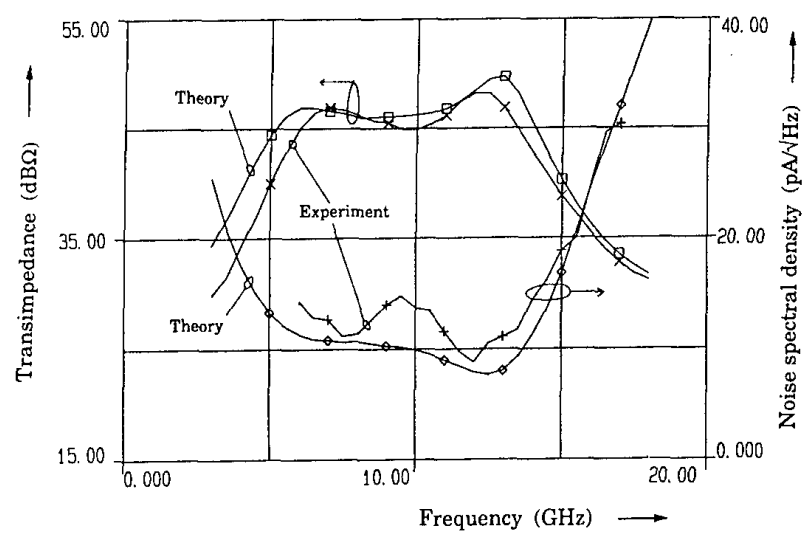

Figure 4. Measurement and simulation of the transimpedance and the equivalent input noise current spectral density of the front-end amplifier. analyzer and from this the equivalent input noise current spectral density was derived. The measurements are shown in figure 4 and excellent agreement between measured and simulated results were obtained. To the best of our knowledge, this is the first time such a good agreement has been obtained for hybrid optical front-end amplifiers at such high frequencies.

\section{SYSTEM EXPERIMENTS}

The front-end amplifier was used in a $2.5 \mathrm{Gbit} / \mathrm{s}$ coherent CPFSK system experiment. The experimental set-up is shown in figure $5[9,10]$. The transmitter consisted of a commercially available distributed feedback (DFB) laser. The local oscillator as a multi-quantum-well (MQW) DFB laser. The total laser linewidth was $35 \mathrm{MHz}$. Optical isolators were employed to prevent back reflections into the lasers. Manual polarization control was used to match the optical polarization of the transmitter and local oscillator lasers. The optical signals were combined in an optical fiber coupler and one of the output arms was used to couple the light into the front-end photodiode. The output signal of the front-end was amplified and filtered. Part of the IF signal was used in an AFC control loop to lock the local oscillator signal frequency to the incoming transmitter signal frequency, with a stable IF [4]. The other part of

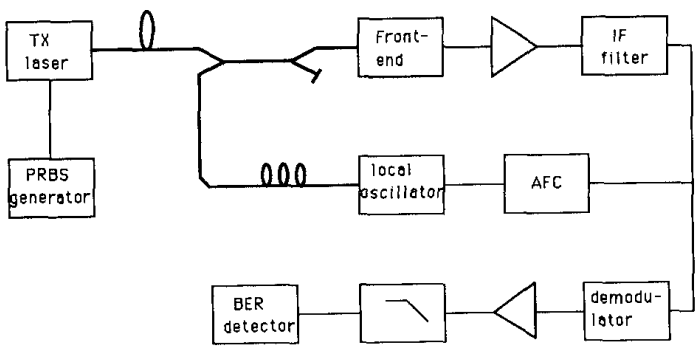

Figure 5. Experimental set-up of the $2.5 \mathrm{Gbit} / \mathrm{s}$ CPFSK coherent optical system experiment. 


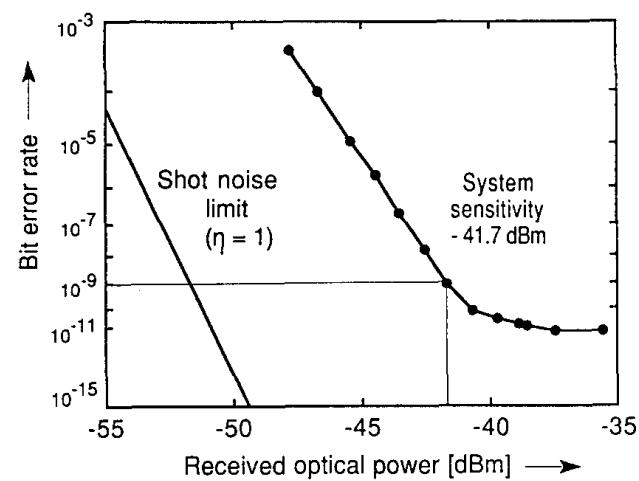

Figure 6. Bit error rate as a function of the received optical power.

the IF signal was demodulated in a delay-andmultiply IF detector. The thus obtained baseband signal was amplified and filtered.

The bit error rate (BER) measurement results are shown in figure 6, together with the theoretical shot-noise limit for perfect coupling and quantum efficiency. A system sensitivity of $-41.7 \mathrm{dBm}$ at a BER of $10^{-9}$ was measured. As seen in figure 6, a BER floor was observed, which is due to the laser linewidth used in this experiment. The system sensitivity deviates $10 \mathrm{~dB}$ from the theoretical shotnoise limit. Part of this $(1.8 \mathrm{~dB})$ is due to the fact that the local oscillator shot-noise not completely dominates the amplifier noise from the front-end. The system performance could be improved if a smaller modulation index could be used and the IF bandwidth could be reduced form the present 5 $\mathrm{GHz}$ to approx. $2.5 \mathrm{GHz}$. This would require lasers with smaller linewidth. This improvement would also reduce value the BER floor.

\section{CONCLUSION}

A 7 - $13 \mathrm{GHz}$ low-noise tuned optical front-end amplifier has been made, showing $46 \pm 1 \mathrm{~dB} \Omega$ transimpedance, and an equivalent input noise current spectral density around $12 \mathrm{pA} / \mathrm{NHz}$. This is the first time such a flat response and low noise was obtained simultaneously at these high frequencies, without any further equalization. A new lay-out technique enabled close monitoring of each manufacturing step and excellent agreement between the measurements and simulations were observed. Commercially available components were used. We believe this is the first time the concept of bandpass tuned optical front-end is verified in this frequency range. The front-end amplifier was used in a $2.5 \mathrm{Gbit} / \mathrm{s}$ coherent CPFSK system experiment. Bit error rate measurements show a system sensitivity of $-41.7 \mathrm{dBm}$ at $\mathrm{BER}=$ $10^{-9}$

\section{ACKNOWLEDGEMENTS}

The authors would like to thank the Institute of Microelectronics in Sweden for the three-electrode laser and Hitachi Central Research Laboratory in Japan for the MQW DFB laser. Also, we wish to thank Prof. Palle Jeppesen, Dr. Gunnar Jacobsen and Erik Bødtker for guidance and encouragement.

\section{REFERENCES}

[1] G. Jacobsen, J.X. Kan and I. Garrett, "Tuned front-end design for heterodyne optical receivers", IEEE J. Lightwave Technology, 1989, p. 105-114.

[2] J.L. Gimlett, "Ultrawide bandwidth optical receivers", IEEE J. Lightwave Technology, 1989, p. 1432-1437.

[3] N. Takachio and I. Iwashita, "A novel resonance-type optical receiver for high-speed optical heterodyne transmission systems", IEEE J. Lightwave Technology, 1989, p. 1371-1378.

[4] B. Christensen, G. Schiellerup, B.F. Jørgensen and K.H. Andersen, "Multivariable state feedback AFC for a 2.5 Gbit/s CPFSK coherent optical communication system", Proceedings 15th ECOC, Amsterdam, 1990, p. 339-342.

[5] G. Schiellerup and M. Høgdal, "System specification for a coherent $2.5 \mathrm{Gbit} / \mathrm{s}$ CPFSK system experiment", E.M.I. report, R 425, 1990.

[6] C.J. Mahon, G. Schiellerup and R.J.S. Petersen, "Simple, all fiber optical image-rejection mixer for optical heterodyne receivers", Proceedings 15th ECOC, Amsterdam, 1990, p. 1029-1032.

[7] D. Wake, R.H Walling, L.D. Henning, D.G. Parker, "Planar junction top-illuminated GaInAs/InP PIN photodiode with bandwidth of $25 \mathrm{GHz}$, Electronics Letters, 1989, p. 967-969.

[8] R.J.S. Petersen, U. Gliese, B. Broberg and S. Nillson, "Characterization of a $1.55 \mu \mathrm{m}$ three electrode DFB laser", Proceedings 15th ECOC, Amsterdam, 1990, p. 279-282.

[9] G. Schiellerup, Ph.D. thesis, E.M.I. report, 1991.

[10] M. Høgdal, Ph.D. thesis, E.M.I. report, 1991 